\title{
Evaluation of total hip replacement using cementless porous-coated metal cups after acetabular fractures
}

\begin{abstract}
Introduction: Total hip replacement (THR) following acetabular fracture has a special difficulty regarding the longer duration of operative procedure and the presence of hardware used in fixation of acetabular fracture.

Patients and method: Fourteen patients were included in this prospective study that gave a history of acetabular fracture and were surgically treated with THR using porous- coated metal cups. The mean age was 52 years. The mean interval between initial acetabular fracture and THR operation was 6 months. The minimum follow up was 24 months.

Results: The mean Harris hip score improved from 34 preoperatively to 83 postoperatively. No registered cases of dislocation during the follow up period. Two cases showed Brooker type I dystrophic calcification postoperatively. No case showed progressive radiolucent lines in the radiological follow up. Porous- coated metal cups gave encouraging clinical and radiological results after a minimum of 24 months follow up.
\end{abstract}

Conclusion: Longer terms follow up is recommended in order to be able to judge the durability of porous- coated metal cups in the treatment of post acetabular fracture THR.
Volume 7 Issue 4 - 2017

Mohamed Nabil

Lecturer of orthopedic surgery, Suez Canal University, Egypt

Correspondence: Mohamed Nabil, Lecturer of orthopedic surgery, Suez Canal University, Ismailia, Ring Road, Suez Canal University Hospital, Egypt, Tel 1009797 I07; Emailnabilhassona@yhoo.com

Received: December 31, 2016 | Published: February 23, 2017

\section{Introduction}

The efficacy of total hip replacement (THR) in the management of post-traumatic osteoarthritis of the hip is well established. ${ }^{1-3}$ Nevertheless, THR following acetabular fracture has its own difficulty in the orthopedic surgical practice regarding the longer duration of operative procedure and the presence of hardware used in fixation of acetabular fracture. ${ }^{4,5}$ The failure rate and need for revision is high when using cemented acetabular cups for patients who had previous acetabular fractures. ${ }^{6,7}$ On the other hand, the clinical and radiological outcomes were satisfactory when using cementless acetabular cups for patients with post-traumatic arthritis. ${ }^{8,9}$ The use of porous coated metal cups has markedly increased in primary and revision THR. ${ }^{10-13}$ The current prospective study presents the clinical and radiological outcomes of porous coated metal cups in total hip replacement in patients with previous acetabular fracture.

\section{Patients and methods}

This prospective study included fourteen patients who had previous acetabular fracture and underwent total hip replacement. Cementless porous coated metal cups were used in all patients. The male to female ratio was 1:1 (seven males and seven females). The patients were classified regarding the time elapsed from fracture till THR operation according to Mears ${ }^{14}$ into acute, subacute and chronic fracture patients. The Harris hip score (HHS) was the standard method of clinical and functional evaluation pre and post operatively. ${ }^{15,16}$ The primary clinical endpoint was the need for revision surgery for any reason. The radiological evaluation included assessment of injury $\mathrm{x}$-rays, pre and postoperative fracture fixation x-rays, and serial x-ray assessment after THR. ${ }^{17}$ The incidence of heterotopic ossification and hardware failure were also reviewed in X-rays. ${ }^{18}$

\section{Surgical technique}

Preoperative planning involved obtaining Judet views and CT scan with 3 -D reconstruction to aid in reconstructive planning and to en- sure the integrity of the posterior and anterior acetabular columns. A posterolateral approach to the hip was used in all cases. Intraoperatively, fluoroscopy was used to identify the bony landmarks which may be masked in the presence of excess fibrous tissue or heterotopic ossification. Clearance of the acetabular socket from excessive fibrous tissue was achieved using curette and diathermy cautery. Acetabular reaming was then done until having a bleeding bone. Cancellous bone autograft (driven from the excised head of femur and during preparation of the proximal femur) was packed in the deficient parts of the acetabular socket and reversed reaming was used to obtain homogeneity. The final cup was secured in position using 2-3 screws fixation.

\section{Results}

The mean age at surgery was 52 years (range 36-64 years). Total hip replacement was done after an average time of 6 months (range 2 weeks to 14 months) from fracture. The postoperative follow up lasted for a minimum of 24 months (range 24-28 months). Three patients had simultaneous plating of the acetabular fracture and acute THR. Nine patients had plating of acetabular fracture at least 6 months prior to THR operation. Two patients had THR after conservative treatment of prior acetabular fracture. Autogenous bone grafts (derived from femoral head and proximal femoral preparation) were used in all patients. The average blood loss was $620 \mathrm{~mL}$ (range 450-950 mL). The mean Harris hip score improved from 34 preoperatively to 83 postoperatively $(\mathrm{p}=0.01)$. No registered cases of dislocation during the 24 months follow up period. Two cases showed Brooker type I dystrophic calcification postoperatively. No case showed progressive radiolucent lines around the porous coated acetabular cups in the radiological follow up (Figure 1a\&b). The mean leg length discrepancy after THR was $4 \mathrm{~mm}$ (range $0-10 \mathrm{~mm}$ ).

\section{Discussion}

Fixation of acetabular fractures in the presence of osteopenia, past history of pelvic irradiation, and poor bone quality have usually posed special difficulties to the orthopedic surgeon. Total hip arthroplasty 
after fixation of acetabular fracture gives added challenge of retained hardware, poor bone stock and previous surgical intervention. Several previous studies have evaluated the use of cementless acetabular components but not specifically the porous-coated metal acetabular components in THA for post acetabular fracture osteoarthritis. The current study presents a series of 14 cases of porous-coated metal cups with a minimum of 24 months of clinical and radiological follow-up.

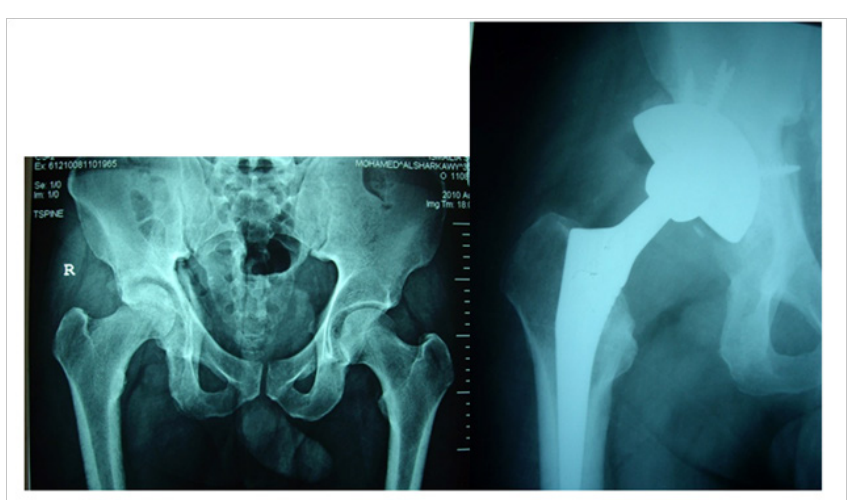

(a)

(b)

Figure I (a) preoperative $x$-ray showing arthritis of the right hip after acetabular fracture, (b) post-operative x-ray showing the use of cementless THR with porous-coated metal cup.

Ranawat et al. ${ }^{19}$ managed 32 patients using cementless cups after acetabular fractures. Twenty-four patients had open reduction and internal fixation prior to total hip arthroplasty, while 8 patients did not have initial fracture fixation. They reported a revision rate of $19 \%$; one case had aseptic cup loosening. Peri-acetabular radiolucencies were reported in 5 cases. Bellabarba et al. ${ }^{9}$ in their study had 30 patients who had THA following acetabular fracture. They reported no significant difference between the acetabular fracture fixation and non fixation groups $(\mathrm{p}=0.39)$. They reported a revision rate of $3 \%$ for aseptic loosening. Mears \& Velyvis ${ }^{14}$ evaluated 57 acute THA following displaced acetabular fractures after 2 - 12 years of follow up and concluded that THA following acute acetabular fractures can restore function and relieve pain.

Berry \& Halasy ${ }^{20}$ evaluated 34 cementless titanium porous-coated THAs following acetabular fracture with a follow up of 10 - 16 years and concluded that cementless cups show acceptable aseptic loosening rates. Their results are matching with the results of the current study.

Porous-coated acetabular cups have increased potentiality for improving biologic fixation. ${ }^{13,21-24}$ The use of porous-coated metal cups proved to be successful in providing secure acetabular cup fixation as demonstrated in the literature. ${ }^{12,13,25-27}$ Furthermore, porous-coated acetabular cups bear resemblance to normal physiological force distribution. This could limit the effects of stress-sheilding, offer increased bone mineral density, and reduce osteolysis. ${ }^{28,29}$

Although cemented and cementless cups may reveal comparable results in typical primary THA, there are few studies considering THA following acetabular fracture. No study unswervingly matches cemented versus cementless cup fixation following acetabular fracture in a sole cohort. ${ }^{30}$ One study observed the usage of impaction grafting and cement for fixation after acetabular fracture ${ }^{31}$ which seems a feasible option at long term follow-up but is definitely technique dependent.

The strength of the current study is related to the use of a single porous-coated metal acetabular component in a single-surgeon series.
In this small number of patient series at short term follow up, porous-coated metal acetabular implants offered encouraging clinical outcomes in the majority of patients. With increased cohort and longer follow up, porous-coated metal components may demonstrate a feasible choice in the management of post-traumatic arthritis in patients with former acetabular fracture.

\section{Acknowledgments}

None.

\section{Conflicts of interest}

None.

\section{References}

1. Conventry MB. The treatment of fracture-dislocation of the hip by total hip arthroplasty. J Bone Joint Surg. 1974;56(6):1128-34.

2. Malkin C, Tauber C. Total hip arthroplasty and acetabular bone grafting for unreduced fracture-dislocation of the hip. Clin Orthop Relat Res. 1985;201):57-59.

3. Boardman KP, Charnley J. Low-friction arthroplasty after fracturedislocations of the hip. J Bone Joint Surg Br. 1978;60(4):495-497.

4. Zhang L, Zhou Y, Li Y, et al. Total hip arthroplasty for failed treatment of acetabular fractures: a 5-year follow-up study. J Arthroplasty. 2011;26(8):1189-1193.

5. Mortazavi SM, Greenky R, Bican O, et al. Total hip arthroplasty after prior surgical treatment of hip fracture is it always challenging? $J$ Arthroplasty. 2012;27(1):31-36.

6. Romness DW, Lewallen DG. Total hip arthroplasty after fracture of acetabulum: Long-term results. $J$ Bone Joint Surg Br. 1990;72(5):761-764.

7. Weber M, Berry DJ, Harmsen WS. Total hip arthroplasty after operative treatment of an acetabular fracture. J Bone Joint Surg Am. 1998;80(9):1295-1305.

8. Oujie L, Yang J, Shen B, et al. Midterm results of uncemented acetabular reconstruction for post-traumatic arthritis secondary to acetabular fracture. J Arthroplasty. 2011;26(7):1008-1013.

9. Bellabarba C1, Berger RA, Bentley CD, et al. Cementless acetabular reconstruction after acetabular fracture. J Bone Joint Surg Am. 2001;83(6):868-876.

10. J Joglekar SB1, Rose PS, Lewallen DG, et al. Tantalum acetabular cups provide secure fixation in THA after pelvic irradiation at minimum 5year follow-up. Clin Orthop Relat Res. 2012;470(11):3041-3047.

11. Bobyn JD, Poggie RA, Krygier JJ, et al. Clinical validation of a structural porous tantalum biomaterial for adult reconstruction. $J$ Bone Joint Surg Am. 2004;86(suppl 2):123-129.

12. Sporer SM, Paprosky WG. The use of a trabecular metal acetabular component and trabecular metal augment for severe acetabular defects. J Arthroplasty. 2006;6(suppl 2):83-86.

13. Mulier M, Rys B, Moke L. Hedrocel trabecular metal monoblock acetabular cups: mid-term results. Acta Orthop Belg. 2006;72(3):326-331.

14. Mears DC, Velyvis JH. Acute total hip arthroplasty for selected displaced acetabular fractures: two to twelve-year results. J Bone Joint Surg Am. 2002;84(1):1-9.

15. Klassbo M, Larsson E, Mannevik E. Hip disability and osteoarthritis outcome score. An extension of the western Ontario and Mcmaster universities osteoarthritis index. Scand J Rheumatol. 2003;32(1):46-51. 
16. Amstutz HC, Thomas BJ, Jinnah R, et al. Treatment of primary osteoarthritis of the hip: a comparison of total joint and surface replacement arthroplasty. J Bone Joint Surg Am. 1984;66(2):228-241.

17. DeLee JG, Charnley J. Radiological demarcation of cemented sockets in total hip replacement. Clin Orthop Relat Res. 1976;(121):20-32.

18. Brooker AF, Bowerman JW, Robinson RA, et al. Ectopic ossification following total hip replacement: incidence and a method of classification. J Bone Joint Surg Am. 1973;55(8):1629-1632.

19. Ranawat A, Zelken J, Helfet D, et al. Total hip arthroplasty for posttraumatic arthritis after acetabular fracture. $J$ Arthroplasty. 2009;24(5):759-767.

20. Berry DJ, Halasy M. Uncemented acetabular components for arthritis after acetabular fracture. Clin Orthop Relat Res. 2002;(405):164-167.

21. Bobyn JD, Pilliar RM, Cameron HU, et al. Osteogenic phenomena across endosteal bone-implant spaces with porous surfaced intramedullary implants. Acta Orthop Scand. 1981;52(2):145-153.

22. Bobyn JD, Stackpool GJ, Hacking SA, et al. Characteristics of bone ingrowth and interface mechanics of a new porous tantalum biomaterial. J Bone Joint Surg Br. 81(5):907-914.

23. Bobyn JD, Engh CA. Human hitology of the bone porous metal implant interface. Orthopedics. 1984;7:1410-1421.
24. Hacking SA, Bobyn JD, Toh $\mathrm{K}$, et al. Fibrous tissue ingrowth and attachment to porous tantalum. JBiomed Mater Res. 2000;52(4):631-638.

25. Kremers HM, Howard JL, Loechler Y, et al. Comparative long-term survivorship of uncemented acetabular components in revision total hip arthroplasty. J Bone Joint Surg Am. 2012;94(12):e82.

26. Komarasamy B, Vadivelu R, Bruce A, et al. Clinical and radiological outcome following total hip arthroplasty with an uncemented trabecular metal monoblock acetabular cup. Acta Orthop Belg. 2006;72(3):320-325.

27. Del Gaizo DJ, Kancherla V, Sporer SM, et al. Tantalum augments for Paprosky IIIA defects remain stable at midterm follow up. Clin Orthop Relat Res. 2012;470(2):395-401.

28. Meneghini RM, Ford KS, McCollough $\mathrm{CH}$, et al. Bone remodeling around porous metal cementless acetabular components. J Arthroplasty. 2010;25(5):741-747.

29. Meneghini RM, Meyer C, Buckley CA, et al. Mechanical stability of novel highly porous metal acetabular components in revision total hip arthroplasty. J Arthroplasty. 2010;25(3):337-341.

30. Bobyn JD, Toh KK, Hacking SA, et al. Tissue response to porous tantalum acetabular cups: a canine model. J Arthroplasty. 1999;14(3):347-354.

31. Schreurs BW, Zengerink M, Welten ML, et al. Bone impaction grafting and a cemented cup after acetabular fracture at 3-18 years. Clin Orthop Relat Res. 2005;(437):145-51. 